\title{
On the Performance of National Vocal Music Art
}

\author{
Xiaoying Guo \\ Department of music, Nanchang Normal University
}

\section{Keywords: Quyi Rap; Drama Rap; Folk Song Singing}

\begin{abstract}
The performance of national vocal music has unique connotations and characteristics, which are shown from the subjects' expression of emotions to the essential characteristics of objects as well as the mutual penetration of subjects and objects. The process and normal form of national vocal music's artistic expression refers to emphasize on the subject's emotion and performance before the sound and then demonstrate the song's contents and artistic conception through singing with human's voice as the carrier. At the level of national vocal music's artistic behaviors, the singing techniques show linear flow. The linear singing of national vocal music art contains a wealth of emotion of life, and its vivid mood has an isomorphic relation with the heaven... This paper puts aside controversy and discusses expressiveness from a broader sense, including the connotation of ancient songs, primordial songs of the Han nationality, folks of each nationality, traditional operas and creative songs, etc.
\end{abstract}

\section{Introduction}

About arts, as Marx pointed out in "Economics in 1844-Philosophic Manuscripts", "Arts are just a special form of production dominated by the universal law of production." And a particular art (group) also has its own "universal law". Therefore, in order to understand an art (group), it is necessary to understand the "universal law" of producing this art, that is, its way to master arts.

Traditional Chinese arts prominently reflect this characteristic of performance. 1. It cannot only be embodied in the emphasis of emotions of the subject in creation arts; 2 . It is also embodied in the mood reflected by the object in art appreciation. To be specific, in terms of poetry, it is advocated poetry performance subject emotional of "on love to poem" ( $\mathrm{Lu} \mathrm{Ji}$ "Wenfu") and pursuit poetry and universe object without even realizing it communicates of "poems who, world of heart also" ("Poems Latitude") of unified; in terms of painting, both from "outside division of nature, have heart source" of subject is meaning for creation of S upreme guidelines, and "to a tube of pen, intends body of the universe" (Wang Wei "On Painting”), sought object painting outside of like of charm; dance, outside seeking song, and round, and twist, and pour of expression sex action language, within told gas and spirit, extension value within a common unified in function; on calligraphy, both "the emotion described, taking charm" (Sun Guo-Ting "the Book Charts"), also praised the "book of the wonderful, God color for it, followed by quality" (Wang Seng-Qian "Praise of the Pen") deficiency caused by the object. In short, during the long ancient societies, traditional Chinese art, Verve is in pursuit of emotional expression on the subject and object trajectory on the development and maturation of dialectical unity. Obviously, it is different from the Western emphasizing on the object of imitation of ancient art, and understanding of reproduction and character.

Under the influence of Chinese cultural atmosphere and spirit of art, stable style characteristics and aesthetic appearance have formed in traditional Chinese music, and expressiveness is its 
important feature. It is stated in the beginning of "On Music" that "where the sound, and also by the people. People move, make it so. Sense to move, so the acoustic is produced. Accordingly, it changed into, is known as the sound." This proposition is clearly illustrate the expression of music derived from a person's inner feelings. In this book, "music, heaven and" thesis is from one perspective, finding a rhyme by outside, and the beauty of harmony of the universe. The transcendence of its beauty is the advanced features of beauty (sense of beauty).

Chinese people's aesthetic taste tends to be synthesis: the stories are poetry, painting, blending poetry, calligraphy and literature, and so on. Is melting melodies, poetry, voice and singing as one of the arts, would gain from which overlap the aesthetic enjoyment, and more acceptable to the Chinese.

From ancient folk songs and the poetry of homologous relationship to recent times that never takes a holiday tradition of combining music and literature, "the Book of Songs" in the State wind came from folk songs; continue to collect poems and folk songs of Han music collection, for placement of imperial court music; the Tang poem, the song CI or the Yuan drama and music recitals, singing. It is regrettable that, because of historical guilt is not very good technology and measures to save the tune, the cultural heritage of their ancestors are inherited only from the literary value. If you are the "3,000 short, 40 large curved" 1 handed down can become a sound, and then China's integration of folk songs has to be part of national life "encyclopedia". Stable agricultural and cultural psychology of Confucian spirit rule, ancient Chinese culture in the academic is "text", does tend to like.

Poetry (lyrics) and melody (music) combine to complement each other. In essence, the lyrics and music (melody) is a contradiction of mutual restraint: the charm of music that indescribable sound, deep human emotions slight blur visual display, which is specific sense of human emotions and unpredictable may unspeakable nature stable fit. Music's strengths are in its jumps, power, emotional, this is just the weaknesses of poetry. Because, again vivid rhetoric is conceptual, not finely reflect the mood of people micro "delicate thoughts".

The basic unit of Chinese language is monosyllabic, words, making sentences with great flexibility and initiative. Division and stretching elastic word itself can be condensed out of rhythm. Poetic language single complex consistency, short length match, tidy in the see varies, but also because ze metrical norm, so the lyrics "land can be used for stone throwing" - has quite melodic and rhythmic tendencies. It can be said that Chinese language itself provides an important bas is for the formation of tunes.

Once upon a time, the National Vocal Music in Chinese traditional art of the forest is what peak. Unfortunately, the old audio data is not available, and the text data is very small. This is the study of the history and properties of national vocal music create a barrier. Make the study of contemporary vocal music of the nation become more concentrated in the areas of technical skills in order to practice as a guide, and research on music history and vocal aesthetic relatively weak. It is still stuck in the vocal aesthetic form theory (such as melodic beauty, rhythm beauty, beauty line cavity, pronunciation US) in superficial level. I wanted to break this pattern, but unfortunately time, energy, knowledge structure and reserves less, do not systematically arranged vocal theory, work to fill the gaps. Just select performance characteristics discussed on the level of cut from the grasp of people, with meager force, which can be seen from a glimpse.

Title: Music is the passion of the art, can be particularly profound impact on people's strong feelings and experience, this is the particularity of the decision by the music. There is no word to 
express their thoughts and feelings as the era of national traditions and fundamental purpose for kind of art of singing in the world, no not to express. To this end, the singer is trying to express the connotation of the lyrics and music mood. Regardless of China's ethnic vocal music or Western style BelCanto, they are seeking the meaning of the word expression of sound language skills of beauty and beauty line cavity, which is composed of two cornerstones of Vocal Arts. The national vocal music also has the unique value orientation for the word and the sound of pursuit.

Chinese vocal highlights the clear language, and the formed singing voice directed by the words on the aesthetics character of China (also to enunciate, cavity with the word go, round the neck cavity) is positive, after the aesthetic pursuit of beauty.

To make clear articulation and a mellow and full tune, traditional vocal training vocal music, especially Opera summarizes a set of concise specifications of "oral law": the positive tone, four sounds to identify tones and rhymes of yin and Yang. Specific to, out word about word of "spray mouth" "drive", word head to fast, and short, has mouthpiece tooth teeth lip different of into resistance way; articulation "introduction long" to has "mouth force", Word abdominal introduction long has opening and closing align pinch embouchure Shang of specification; word tail to received word owned rhyme, the vocal in China has always been combined with poetry closely, so singing owned rhyme early has "North to Central Plain of China, South cases Hongwu", later and summary has drama 13 point. 13 point can be finely divided into exhibition as well, grabbing lip, hard, straight pipes, arrived from the sound, jaw and nose several major categories. Singing, in order to make the voices through, mellow, smooth, according to their different characteristics, pronunciation method also can be subdivided into branches, before and after, width, and so on. It can be said that skill of enunciation in singing as the characters themselves flexibility, variety, and no more rules.

It is not only the technical guarantee of the sound beauty of the word, but also the national vocal music in the whole sense. The essence of the national vocal music art is the expression of the essence of the national vocal music art.

An art of singing expresses thoughts and feelings of the nation and era everywhere. The difference is that emotional expression logical way. The voice in advocating paranoia in the aesthetics is sound, word perfect technology, a matter of course to complete emotional expression. Aesthetic trend is, "love the sound of a word." In China, the expression is the primary function of the various kinds of art. National vocal music, it is typically pursue a "love - the word out" the aesthetic value orientation. Namely: "quasi-Qing, born in word, made for the sound chamber."

Practice singing, in order to highlight the expression of emotion, often can be ignored breath and other techniques. Even visits from a scientific point of view there will be some deviation vocalizations, but technically shortcomings often be compensated by the expressive function, and another meaning.

Emotion is the 'four subjective attitude of objective reality " $3 / 4$, " is a human object and phenomena of reality are fit for human needs and social needs arising from experience. "Psychological research shows that the main emotion obtained from the perception began. Outside perception of stimuli in the brain caused by galvanic reflected wave layer, like a stone thrown into water and the introduction of ripples, but after constantly stimulate the body will produce all kinds of specific internal recoil feeling back. It is worth noting that the main object of perception to reflect on all the details is not the object, but only the "pen has been ill and is intended week" (Zhang Yanyuan "Art History Theory") because of the person because due different places, presented the main object style (characteristic) varies. For this reason, emotion has a vivid 
National vocal music art to expressions in the first place, is the principal object of the Guide, quality instructional technology course. Before the sound comes up and emphasizes the emotional exuberance, again with vocals, as carriers, render the content of songs and mood-this is the paradigm of national vocal music performance process.

Put "emotion" in the first place and the actual "people" as the center, emphasizing the centrality of man in the universe. This Yang overflowing with full-bodied flavor of the humanistic spirit of singing (as opposed to reverence to God's ancient religious society in the West), is the traditional "harmony" thoughts in vocal performance and aesthetic reflection, is where the value of the vocal artistic features.

Lines are the basic element of formal beauty. Art line usually refers to calligraphy, painting and other visual arts varieties. Music category line refers to a time in the flow line with sound. Borrowing the concept of "line" describe China's auditory art refers to the melody characteristic of traditional Chinese music, Western music to distinguish it from the massive, three-dimensional morphology harmony. Discussion of Chinese music has a lot of linear, this will not repeat. Hereinafter, the selected linear aesthetic of traditional music category of Vocal Arts as discussed object. Moreover, the study does not form layers in tuning tonality, notation, etc., but based on practice singing, singing at the level of behavior, from singing technical skills of analysis, and discussion of national vocal linear performance and value.

The syllabic features of Chinese language, tonal characteristics, perception and pho nological features of dialect and language requirements for mood, atmosphere, common singing was unique in that the infinite fluctuations of coherent States, vocal singing thus showing a linear flow on the stereo. This is due to:

1. Syllables and singing. Chinese are Mono-syllable, which means each syllable consists of prefix, Word Web, end of Word composition. These components vary in location, function in the singing. Word Web made up of vowels, and is a core part of the syllable, sound great, most long time, best extended, also called sang in high spirits. By prefix, and suffix consonant (or consonant sound), bad music, is a minor part, but assume the Mission of connecting words with the transition. Head sings the words clear, short, and "virtual" and "fast"; suffix's important mission is to rhyme, so that the whole syllable intact and clear, so "light" and "quasi", at the same time should also pay attention to keep the resonance with the prefix of a Word under cohesion.

2. Tones in Chinese and singing. Character is an indispensable character meaning difference between Chinese characters, which is bound to corresponding changes in pitch. Liu elaborated in the Indian test record of when the Chinese Pinyin Tone feature, think mobile is sliding, not beating that level of sound.

3. Phonetic rhyme and sing. In the Chinese vowel, purely vertical die only two: Ou remaining cross-shape: a,I occupies an absolute scale.

4. Chinese phoneme pronunciation and singing. On the Chinese language generally in front of the tongue, and concentrated in the front and middle of the mouth, consonants and vowels is naturally closely connected and easy to bond. So sing the phoneme pronunciation of transformation is small and agile, clear sound clever, so resonates with cheerful, but not full.

Color refers to the color and sound characteristics. One voice of the ever-changing, both related to innate pronunciation materials, also acquired with the manner of articulation and aesthetic differences. Features of national vocal timbre, it greatly enhances their individual development. 
1. National vocal music is featured by bright, focused and crispy sound with "front" as the property.

2. Rich sound changes and personalized pursuit. Under the leader of "front" sound, there are differences in the voices of different regions, different opera types, different genres, different industries and even different places in the same song.

3. Classic ways to adjust the tone include:

(1) Using both true and false sound.

(2) Place of producing sounds.

(3) Adjustment of resonance cavity.

(4) Control of breathe.

(5) Formation of resonance focus

Tone adjustment can also be done by means of Tunes. Runqiang, is a tune retouching, contrast, rendering, rich supplement to make up for the dull tunes. Adjust both contradictory pronunciation and melody, and also played the main emotion song to characterize the image, the pursuit of charm, just like the so-called "music of Peter grid in the song, but the luster in the singing" ("Fang Zhu shop melody"). "Singing" in "every song is heard, the sound has four sections; from the end; transition; temperature for the" where "temperature for the" original intent when the needle is inserted to wear jewelry, to be good at singing by analogy shoot flexible plug cavity, namely Tunes.

Psychological research shows that people's inner feelings are a "flow." In the West, there is the famous "stream of consciousness" theory. US W James proposed a "thought stream, the stream of consciousness or subjective life and his ilk" in 1890 published "Principles of Psychology", which is a more exact, precise and appropriate metaphor for the state of the flow of water made mental activity.

"Qi" concept in Chinese culture is almost everywhere: "I'm good at keeping my noble spirit" (Mencius), "the world has righteousness" (Wen), "momentum", "vigour" and so on. This ancient society of "man corresponding to universe" philosophy of harmonic development of man and nature are closely linked. "Qi", in the framework of a bridge between man and. It can be said that "qi" in traditional Chinese culture is a unique and rich connotation of the concept. Scholar ye lang thought of aesthetics in the Wei-Jin aesthetics, "Chi" has three aspects: "1.' ' is a category of General artistic origin;" 2.' It is a category of General vitality and creativity of artists "; 3. It is a category of General artistic life. "The author thinks that the "vivid" and "qi" is the third meaning of the expression. Taiwan scholar Xu fuguan's thought '"air' is the artist's inner vitality outside of a force". Two statements highlighted the life (force) of significant importance.

"Vivid" to sing, the typical approaches (except the tune tools) are:

1. Break the ventilation of commas.

2. Loose and tight rhythms.

3. "Sing" full stop cleverly.

4. Use the character "jian" cleverly.

5. Disposal of cadence.

6. The application of "prolonged tune".

7. The application of the sound "er".

In a harmonious way, implicitly and organically singing, the actual situation matched, fuzzy information by passing semantic and non-semantic lyrics information provided can impact people's listening, visual senses, cause indirect, vague and subtle effects to the aesthetic psychology, so the singing (sound) rises toward a higher spiritual realm. This is the "Lively" quality show in the 
national vocal music. It relies on melody, rhythm, strength, lyrics to the performance, but not the melody, rhythm, strength, or the simple sum of the lyrics themselves. It is often outside the external acoustic sound rhyme cause. It can be said that to sing "lively" is the supreme state of singing national vocal music.

\section{Conclusions}

In terms of the richness and utility of national vocal music art, it contains multiple connotations, including not only synchronic-solidification morphology, (original form), aesthetics, cultural awareness ... but also diachronic carries multiple factors-singing technique (behavior), sound patterns, stunt...National vocal music is just such a concrete, three-dimensional, multidimensional, fluid, rich, and dynamic integrated quality systems.

Arts are a complex and multilayered system, so it not only allows but indisputably requires a series of scientific efforts ". Therefore, for the investigation of national vocal music, there should be a profound quality system. If only summarized or elaborated from the performance characteristics of national vocal music is obviously the elephant, is slanted.

What is the significance of this paper?

Like arts, national vocal music in the long historical process, from morphological, behavioral, ideas on the finest aspects of continuous distribution, and change. However there also has a constant mass, it is rooted in the Chinese culture of fertile land, prescriptive and constant malleable. I think parenchyma of the national vocal music performance feature. Understanding and analysis of the performance of national vocal music from past and present have emerged from the review of theory, aesthetics, but are scattered about in the form. System to organize, refine results, discussed under the cate gory of national vocal music in performance, to a comprehensive display of national vocal music art parenchyma, is wanted to write this article in the first place, also be the meaning.

The whole paper can be summed up as a linear singing of vocal art, which contains a wealth of emotions of life, and its spirit of vividness of mood and Da Hua Qi have an isomorphic relationship between heaven and Earth. As a saying goes, "character is high, the spirit had to high, the spirit is high, between lively and had to". National vocal performance fully demonstrates China's beauty: life (force) sing out vivid sound, reflecting the lively hearts and embodying a vivid universe. Feel the beauty displayed a Chinese-style, which is not merely to remember yesterday and, more importantly, its practice of vocal music of today and tomorrow is also instructive.

\section{References}

[1] Horsley I. Improvised embellishment in the performance of Renaissance polyphonic music[J]. journal of the American Musicological Society, 1951, 4(1): 3-19.

[2] Juslin P N. Five facets of musical expression: A psychologist's perspective on music performance[J]. Psychology of Music, 2003, 31(3): 273-302.

[3] Grout D J, Palisca C V. A history of western music[M]. New York: WW Norton, 2001.

[4] Seaton D. Ideas and styles in the Western musical tradition[M]. Oxford University Press, USA, 2010.

[5] Leonhard C. The Status of Arts Education in American Public Schools. Report on a Survey Conducted by the National Arts Education Research Center at the University of Illinois[J]. 1991. 
[6] LeBlanc A, Cote R. Effects of tempo and performing medium on children's music preference[J]. Journal of Research in Music Education, 1983, 31(1): 57-66.

[7] Bowles C L. Self-expressed adult music education interests and music experiences [J]. Journal of Research in Music Education, 1991, 39(3): 191-205.

[8] Byrnes S R. Different-age and mentally handicapped listeners' response to Western art music selections[J]. Journal of Research in Music Education, 1997, 45(4): 568-579.

[9] Shuler S C. The impact of national standards on the preparation, in-service professional development, and assessment of music teachers[J]. Arts Education Policy Review, 1995, 96(3): 2-14.

[10] LeBlanc A, Jin Y C, Obert M, et al. Effect of audience on music performance anxiety[J]. Journal of Research in Music Education, 1997, 45(3): 480-496. 